\title{
LETTER
}

\section{From Medical Home to Health Home}

KEYWORDS: patient-centered care; primary care; medical home.

J Gen Intern Med 25(11): 1144

DOI: $10.1007 / \mathrm{s} 11606-010-1504-9$

(C) Society of General Internal Medicine 2010

To the Editors:-There are numerous ongoing pilot projects evaluating the patient-centered medical home. ${ }^{1}$ While achieving a designation of "medical home" can be challenging for many providers, the concept is hardly transformative-after all, the medical home model merely describes a higher quality of primary care. Networking individual medical home practices through the sharing of business functions or clinical management resources can lead to greater efficiency in care delivery. ${ }^{2}$ Even greater potential exists in integrating primary care with other medical services to create organized delivery systems for defined populations. ${ }^{3}$ Nonetheless, while the likely health improvements attainable through such integrated medical care systems are significant, they are relatively modest.

Health behaviors and social environment are also powerful factors. They directly influence health status and indirectly influence patients' ability to benefit from the availability of health care. ${ }^{4}$ New models of health care delivery must ensure that patients can access community services that reduce the negative effects of social factors on their health, while maximizing their strengths and resiliency. Medical encounters offer timely and personal opportunities to identify these social influences and to link patients with supportive community services. The need for social services can be identified by reintroducing the longneglected social history aspect of the medical history. Standardizing this process through the use of structured questionnaires has increased referrals, especially when providers are familiar with resources in their local community. ${ }^{5}$
When medical care providers have more knowledge of their patients' social environment, as well as their health and behaviors, medical care takes on a life span approachconsidering the whole patient over the course of his or her life. In doing so, physicians are able not only to prevent illness, but also to promote health and well-being. When medical homes promote health and are linked to other community resources to provide truly comprehensive care, they will have achieved a higher level of quality and will become "health homes," redefining health as a broader term, much like the World Health Organization does. The goal of health care system redesign should be to create high-performing systems of comprehensive, community-oriented care with health homes, not simply medical homes, at their base.

Edward L. Schor, MD, 1 East 75th Street, New York, NY 10021, USA (e-mail: ELS@CMWF.ORG).

\section{REFERENCES}

1. Bitton A, Martin C, Landon BE. A nationwide survey of patient centered medical home demonstration projects. J Gen Intern Med. 2010;25(6):58492.

2. Abrams M, Schor EL, Schoenbaum S. How physician practices could share personnel and resources to support medical homes. Health Affairs. 2010;29(6):1194-1199.

3. Devers K, Berenson R. "Can Accountable Care Organizations Improve the Value of Health Care by Solving the Cost and Quality Quandaries?" Robert Wood Johnson Foundation/Urban Institute Series on Timely Analysis of Immediate Health Policy Issues, October 2009.

4. Bunker JP. The role of medical care in contributing to health improvements within societies. International Journal of Epidemiology. 2001;30:1260-1263.

5. Garg A, Butz AM, Dworkin PH, Rooti AL, Thompson RE, Serwint JR. Improving the Management of Family Psychosocial Problems at LowIncome Children's Well-Child Care Visits: The WE CARE Project. Pediatrics. 2007; 120(3):547-558.

Published online September 3, 2010 